\title{
¿USÓ NIETZSCHE EL PEOR ARGUMENTO DEL MUNDO? \\ UNA INDAGACIÓN SOBRE LAS BASES EVOLUCIONISTAS DEL ANTIRREALISMO NIETZSCHEANO
}

\author{
Did Nietzsche use the Worst Argument in the World? \\ An Inquiry about the Evolutionary Bases of Nietzsche's Antirealism
}

\author{
Antonio Diéguez \\ Universidad de Málaga
}

«Yet surely the only way to treat Nietzsche with respect is to treat him in the same way that he did his interlocutors - audaciously» ${ }^{1}$.

RESUMEN: Uno de los puntales principales de la tesis de la falsificación de Nietzsche está en su epistemología evolucionista, pero, precisamente por ello, esta tesis carece de una fundamentación adecuada, ya que desde consideraciones evolucionistas no hay bases suficientes para sustentar el ficcionalismo de Nietzsche frente a posiciones realistas epistémicas. El argumento implicado en el desarrollo del ficcionalismo nietzscheano es una modalidad del argumento falaz que David C. Stove denominó «la Joya» o «el peor argumento del mundo». Y si bien este argumento no es la única vía que Nietzsche emplea para sustentar su antirrealismo, sí es la principal.

Palabras clave: Epistemología evolucionista - ficcionalismo - peor argumento del mundo - David Stove - verdad

ABSTRACT: Evolutionary epistemology is one of the mainstays of Nietzsche's falsification thesis, but precisely for this reason this thesis lacks an adequate support. From an evolutionary point of view, there are not sufficient grounds to uphold Nietzsche's fictionalism against epistemic realist positions. The argument involved in Nietzsche's fictionalism is, in fact, a variant of the fallacious argument called by David C. Stove «the Gem» or «the worst argument in the world». Admittedly, this is not the only way that Nietzsche takes to uphold his antirealism, but it is the main one.

Keywords: Evolutionary Epistemology - Fictionalism - The Worst Argument in the World - David Stove - Truth

\section{NIETZSCHE, LA JOYA Y EL PRINCIPIO ISMAEL}

Existen pocos concursos filosóficos. Posiblemente esto no es algo que deba lamentarse, dadas las rencillas y las frivolidades que suelen rodear a las competiciones intelectuales, pero ciertamente es algo que nos diferencia a los profesionales de la filosofía de otros colegas académicos, tanto del ámbito de las ciencias como de las humanidades. Hay variopintos concursos literarios, medallas y pre-

1. S. D. Hales y R. Welshon 2000: 5. 
mios científicos a la mejor teoría o mejor descubrimiento del año, pero, con la excepción del premio Kyoto, que no tiene forma de concurso, si no más bien de elección, no me viene a la cabeza ningún premio relevante de filosofía en el que se dé una auténtica competición entre diferentes obras o propuestas filosóficas. Incluso cuando se ha querido premiar con un Nobel a un filósofo, como fueron los casos de Henri Bergson en 1927, Bertrand Russell en 1950 y Jean-Paul Sartre en 1964, se le ha dado el Nobel de literatura. Hace unos años tuvo lugar, sin embargo, un pequeño concurso filosófico que, pese a su carácter casi anecdótico y a lo poco que ha sido comentado, considero de gran interés didáctico. Me refiero al que convocó en 1985 el filósofo australiano David Stove, profesor en la Universidad de Sidney, para elegir el peor argumento del mundo. Los criterios de valoración que eligió fueron tres: la atrocidad intrínseca del argumento, su grado de aceptación entre los filósofos y el grado en el que había escapado de las críticas. Ahí es nada. Hubo, según nos cuenta Stove ${ }^{2}$, diez argumentos que fueron presentados como candidatos, pero el premio se lo llevó — how else? - el que el propio Stove tenía en mente al convocar el concurso y que posteriormente dio en llamar «la Joya» (the Gem). Dice así:

Sólo podemos conocer las cosas:

- cuando mantienen una relación con nosotros

- bajo nuestras formas de percepción y comprensión

- en tanto que caen bajo nuestros esquemas conceptuales

etcétera.

Por lo tanto:

No podemos conocer las cosas como son en sí mismas³

En el fondo, el argumento equivale a decir que, dado que tenemos mente, no podemos conocer; o, dado que tenemos que usar un lenguaje, no podemos hablar de la realidad. Por razones muy variadas, los lenguajes, los esquemas conceptuales, los sentidos, etc., son considerados invariablemente por los defensores del argumento como impedimentos y no como medios para conocer la realidad.

Stove no da noticia de los otros argumentos recibidos (con excepción de $u_{n o}^{4}$ ), y el hecho de que él fuera el juez del concurso permite sospechar a vo-

2. Stove 1995: 66-67.

3. Conviene aclarar desde el principio que la expresión «cosas en sí mismas» no implica, al menos en el modo en que la uso aquí, la atribución de un carácter nouménico a dichas cosas. El noúmeno kantiano es incognoscible por definición y esto es ya una toma de posición con respecto al problema que revisaremos. Por «cosas en sí mismas» entenderemos simplemente el mundo tal como es con independencia de nuestros lenguajes y nuestros pensamientos. Esto permite asumir incluso que lo que los seres humanos consideran habitualmente como cosas dependa de clasificaciones concretas de ese mundo independiente que pueden variar en función de los intereses y objetivos. Admitir la existencia de un mundo independiente que puede ser conocido no obliga a conceder la existencia de una única descripción verdadera y completa del mismo. $\mathrm{O}$, dicho en términos quineanos-putnamianos, cabe negar la relatividad ontológica y defender al mismo tiempo la relatividad conceptual (cf. Kitcher 2001: esp. 25, 27 y 43-53, y Diéguez 2007).

4. El otro que menciona, y cuyos méritos para el premio reconoce, le fue propuesto por Michael Devitt, y dice así: "La gente que habla diferentes lenguajes naturales/científicos tienen teorías diferentes sobre el mundo (o perciben el mundo de forma diferente). Por lo tanto, la gente que habla diferentes lenguajes naturales/científicos viven en mundos diferentes». Los familiarizados con la tesis Shapir-Whorf o con la tesis de la inconmensurabilidad en sus mil versiones habrán reconocido el tema. 
luntad sobre la justicia del resultado, pero eso no hace ahora al caso. Tengamos mejores candidatos al premio o no, y pese a la controvertida personalidad de Stove y a su desmesurada acidez crítica, hemos de reconocer que, tal como está formulado, el argumento es claramente falaz. Para establecer válidamente la conclusión habría que establecer, como premisa adicional, que el hecho de que conozcamos las cosas bajo esas condiciones necesarias que las diferentes versiones del mismo postulan (a través de nuestros esquemas conceptuales, de nuestros lenguajes, de nuestras capacidades cognitivas, etc.) impide conocer cómo son las cosas con independencia de nuestra mente. No hace falta decir que hasta ahora nadie ha probado semejante cosa, aunque sólo sea porque para establecer eso de forma concluyente habría que tener un conocimiento independiente de cómo son las cosas en sí mismas, lo cual parece ser algo imposible según la propia conclusión del argumento; o bien haber aportado alguna prueba indirecta, pero fehaciente, de que nuestras capacidades cognitivas conducen al error sistemático, lo cual tiene toda la pinta de ser un empeño contradictorio ${ }^{5}$.

Pero chan utilizado realmente «la Joya» tantos filósofos como Stove pretende (él menciona en algún momento, entre otros, los nombres de Berkeley, Kant, Schopenhauer, William Hamilton, Poincaré, Bradley, McTaggart) ${ }^{6}$ ? Algo muy parecido al argumento ciertamente lo podemos encontrar en Berkeley (en concreto en el Tratado sobre los principios del conocimiento humano, capítulo XXIII). Sin embargo, y a pesar de que es el primer nombre que se viene a la cabeza cuando uno se enfrenta con este asunto, puede discutirse si está presente en la obra de Kant; y, si lo está, que ocupe un papel central en su filosofía. Como advierte un comentarista favorable a Stove, Kant defiende por otras vías distintas a «la Joya» la incognoscibilidad de la cosa en sí (cf. Franklin 2002). Por otra parte, puede argüirse que, en sus versiones lingüísticas o sociales, ha sido

5. En un análisis más detenido de la cuestión (Stove 1991a), Stove ve la falacia del argumento en intentar derivar algún tipo de verdad contingente a partir de una verdad necesaria. Según su análisis, las posibles premisas del argumento se pueden reducir al enunciado tautológico «Sólo podemos conocer si se satisface la condición C, que es una condición necesaria para el conocimiento", y de ahí se pretende concluir el enunciado contingente «No podemos conocer las cosas como son en sí mismas». Ahora bien, de una tautología sólo puede seguirse otra tautología, y no un enunciado contingente. Por lo tanto, el argumento es falaz. En mi opinión, sin embargo, el fallo del argumento no está en que la premisa sea tautológica, sino en que — como digo - presupone una premisa oculta no probada y sin la cual la conclusión no se obtiene. En efecto, el enunciado «Sólo podemos conocer si se satisface la condición C, que es una condición necesaria para el conocimiento» es redundante, dice dos veces la misma cosa. Podríamos formularlo así: «C es una condición necesaria para el conocimiento, con lo cual sólo podemos conocer si se satisface la condición C». Aquel que sabe qué significa «condición necesaria» no necesita de la segunda parte. Ahora bien, el enunciado puede o no encerrar una tautología en función de si el carácter necesario de la condición C puede establecerse a priori o si, por el contrario, necesita algún tipo de información empírica. Por ejemplo, el enunciado «Sólo podemos encender un fósforo si se cumple la condición consistente en tener un fósforo, que es una condición necesaria para encender un fósforo» es un enunciado tautológico además de redundante; pero no lo sería este otro enunciado: «Sólo podemos encender un fósforo si se cumple la condición de estar en presencia de oxígeno, que es una condición necesaria para encender un fósforo». El propio Stove añade la crítica de que el argumento presupone un «calvinismo cognitivo» para el cual todo conocimiento es malo precisamente porque es nuestro. Si el fallo del argumento fuera el primero, esta crítica estaría fuera de lugar. Por mi parte, creo que es precisamente en este «calvinismo cognitivo» presupuesto y no argumentado donde radica el fallo del argumento. En todo caso, esta discrepancia no afecta en nada a lo que sigue.

6. Cf. Stove 1991a. 
usado por varios filósofos relativistas o constructivistas contemporáneos. Alan Musgrave (1999) no sólo se lo atribuye a Berkeley y a Kant, sino que considera que el argumento está en la base del idealismo conceptual de Hilary Putnam y Arthur Fine, entre otros autores recientes. Y James Franklin (2002) lo encuentra en algunos postmodernistas y deconstruccionistas. El asunto, pues, no es tan claro como puede parecer, y el uso del argumento por parte de ciertos autores es materia controvertible ${ }^{7}$.

Obviamente, este «argumento» no es la única estrategia que ha sido utilizada en la historia de la filosofía para rechazar las pretensiones del realismo epistemológico, esto es, para negar que tengamos un acceso cognitivo a las cosas reales. Ha habido otros y variados caminos para ello. Uno de los más frecuentados ha sido el exigir la carga de la prueba al realismo. Es el defensor de la tesis de que podemos alcanzar algún conocimiento de las cosas tal como éstas son, es decir, el realista, el que debe dar una explicación satisfactoria de cómo se puede afirmar que hay una correspondencia o parecido entre algunas de nuestras creencias y la realidad, dado que no tenemos un acceso independiente a dicha realidad. En tanto el realista no consiga hacer esto (y el seguidor de esta estrategia cree que no podrá conseguirlo nunca) no hay más remedio que rechazar las altas pretensiones cognitivas del realismo y quedarse con algo más modesto (que puede variar entre instrumentalismo, fenomenismo, empirismo constructivo, constructivismo social, escepticismo, y un largo etcétera). Es decir, según esta estrategia, es el realista el que debe convencer a sus rivales de que nuestros esquemas conceptuales, nuestros lenguajes, nuestra fisiología, etc. no nos impiden ver la realidad tal como es. Debe, en particular, dar algún sentido inteligible a la confusa idea de una correspondencia entre ideas (o enunciados) y mundo.

Se puede, por otra parte, recurrir a mejores argumentos contra el realismo que el proporcionado por «la Joya». La cosecha de ellos es abundante, y recorre desde los tropos de los antiguos escépticos a los argumentos recientes sobre la infradeterminación de las teorías por la evidencia empírica, la carga teórica de la observación o la inconmensurabilidad ${ }^{8}$. Sin olvidar, por supuesto, la crítica de Hume a la inducción; el rechazo de la separación objeto/sujeto, que ha contado

7. Puede replicarse, por ejemplo, que Putnam (1994: 297-300) lo rechaza explícitamente, mientras que él mismo se lo atribuye a Rorty. El texto donde lo hace es interesante, porque muestra que en esto Putnam estaba en realidad muy cerca de Stove. Dice así: «En más de una ocasión he discutido la obra de Rorty en mis cursos de licenciatura, y para mi consternación he visto que en su examen final los estudiantes citan a menudo con convicción y aprobación un argumento que considero malísimo. Se supone que este argumento muestra que toda la idea de que nuestras palabras y pensamientos a veces 'concuerdan', o 'corresponden', o 'representan', una realidad exterior a ellos, y a veces no lo hacen, debe ser rechazada como enteramente vacía. La razón dada es que es imposible 'situarse fuera' y comparar nuestro pensamiento y lenguaje con el mundo. El único acceso que tenemos al mundo es tal como es representado por nuestro pensamiento y nuestro lenguaje. [...] Estoy de acuerdo con Rorty en que no tenemos acceso a una 'realidad no-conceptualizada'. Como le gusta decir a John McDowell, no se puede ver el lenguaje 'desde el otro lado', del modo en que sugiere la idea de mirar al lenguaje de uno y al mundo para compararlos. Pero de ahí no se sigue que el lenguaje y el pensamiento no describan algo fuera de sí mismos, incluso si ese algo sólo puede ser descrito describiéndolo [...]».

8. Para una exposición y revisión de la infradeterminación de las teorías por la evidencia empírica, de la carga teórica de la observación y de la inconmensurabilidad, puede verse Diéguez 2005 : caps. 5 y 7. 
y cuenta hoy con partidarios en corrientes de pensamiento muy diversas; la apelación al carácter histórica, cultural o socialmente situado del sujeto; o la muy debatida hipótesis putnamiana de los cerebros en una cubeta como ejemplificación de las consecuencias que se siguen del teorema Löwenheim-Skolem. Todos ellos intentan mostrar, con mayor o menor éxito y aceptación, que el representacionalismo realista según el cual hay un sujeto que, a través de la experiencia, se representa de una forma objetiva un mundo independiente de la mente es una posición insostenible.

Cabe también la estrategia de negar sentido a toda la discusión. Esto es lo que han hecho algunos «eliminativistas» y algunos «quietistas», como los llama Simon Blackburn (2005: 112 ss.). Para los eliminativistas, como por ejemplo los positivistas lógicos, la discusión sencillamente carece de cualquier fundamento y debe ser abandonada; la epistemología debe ser sustituida por un estudio científico de los procesos cognitivos. Para los quietistas, en cambio, la discusión carece de todo interés - no hay ninguna teoría interesante que montar sobre ella- y debe ser abandonada. La epistemología debe desaparecer como disciplina filosófica. O dicho de otro modo, la filosofía debe reorientar su tarea dejando de lado las pretensiones de la epistemología. Como dice Rorty, lo importante para los seres humanos no es cómo alcanzar la verdad, sino cómo ser ciudadanos en una futura democracia auténtica (Rorty 2000: 3).

No es mi propósito ni mucho menos decir aquí algo sobre estas otras estrategias, cuya mera exposición, por no mencionar su análisis, requeriría bastante más extensión que una decena de páginas, y que además han recibido una atención mucho más cualificada que la que yo podría darles. Mi interés se centrará en aclarar en qué medida la crítica de Nietzsche al realismo se basa en la utilización de algo parecido a «la Joya». El asunto tiene cierta importancia porque Nietzsche es, sin duda, una de las fuentes principales del antirrealismo contemporáneo. Su posición epistemológica ha sido caracterizada como un perspectivismo afín al ficcionalismo instrumentalista (cf. Stack 2005: x). No es fácil encontrar hoy en día muchos filósofos que consideren al escepticismo clásico, al idealismo subjetivo de Berkeley o al idealismo objetivo de Hegel como influencias fundamentales en sus posiciones epistemológicas. En cambio, podemos ver claramente la inspiración nietzscheana, expresamente reconocida en muchos casos, en el rechazo al realismo de los autores que caen bajo la designación de "post-estructuralistas», y muy especialmente en sus múltiples seguidores en los Estados Unidos. Si, por tanto, la base en la que Nietzsche fundamenta su crítica al realismo es un argumento inválido, estaríamos en mejor situación para cuestionar el antirrealismo de los que en él se inspiran.

Conviene antes de nada mencionar, aunque sólo sea de pasada, y dado que permitirá clarificar ciertos puntos más adelante, que Nietzsche ha sido acusado frecuentemente de inconsistencia en este asunto; de afirmar cosas que, si se aceptan algunas ideas centrales de su propia filosofía, no podría haber afirmado coherentemente. El propio Stove (Stove 1991b) analizó, aunque sin mencionar a Nietzsche, este tipo de inconsistencia, a la que designó como «Principio Ismael», en alusión al narrador de la novela Moby Dick, que comienza su historia contando cómo todos los tripulantes del Pequod, excepto él mismo, mueren a causa del ataque de la gigantesca ballena blanca. Si Nietzsche sostiene que toda verdad es un tipo de error, o, peor aún, una ilusión, ¿cómo hemos de interpretar estas 
afirmaciones? ¿Son verdaderas o no? Y si lo son, ¿̇porqué ellas sí son verdaderas y toda otra supuesta verdad es una ilusión? ¿Por qué rechaza como ilusoria toda verdad en lugar de sólo algunas cosas tenidas por verdaderas?

El asunto, uno de los tópicos más habituales en la industria exegética del pensamiento nietzscheano, ha dado lugar a numerosas interpretaciones, hasta el punto de que empieza a parecer que todo analista de Nietzsche que se precie ha de tener la suya propia9. Algunas de ellas salvan a Nietzsche de la inconsistencia entendiendo que éste considera como ilusiones sólo cierto tipo de «verdades» metafísicas o trascendentales, entre las que no están, por supuesto, sus tesis filosóficas, que serían «verdades metafóricas», o «experimentales», o «empíricas», o «trans-perspectivistas». Otras interpretaciones intentan salvarlo explicando que lo que Nietzsche hace es rechazar el concepto de verdad como correspondencia — sólo en este sentido, especialmente si se lo toma de determinada forma «metafísica», las verdades serían ilusiones- para poner en su lugar otro concepto de verdad, particularmente, un concepto pragmatista o un concepto deflacionista. Otras distinguen un nivel en el que todas nuestras creencias serían falsas y un metanivel —en el que habría que situar las tesis de Nietzsche- desde el que se puede dictaminar con verdad que no hay verdades en el nivel más básico ${ }^{10}$. Otras, finalmente, como la de Heidegger o la de Derrida, no lo salvan de la inconsistencia, si bien sacan de ello enseñanzas muy diversas. La más común entre estas enseñanzas - y quizás también la menos convincente para los que no han sido previamente dispuestos a dejarse convencer- es que tal inconsistencia es la consecuencia inevitable y, por tanto, no censurable, de intentar derribar la metafísica desde dentro. El único modo de hacerlo sería mediante enunciados metafísicos que minaran su propia autoridad como tales enunciados. La metafísica mostraría así su carácter ilusorio. Las inconsistencias como la señalada, ya fueran buscadas expresamente por Nietzsche o no, serían por tanto parte consustancial de su tarea desmitificadora.

Como puede apreciarse, lo que está en disputa en todo ello es lo más básico. Se trata de saber si Nietzsche asume la teoría de la verdad como correspondencia; si, por el contrario, la rechaza para proponer otra teoría alternativa; si simplemente pretende un uso nuevo del concepto de verdad; o si, en realidad, no hay en su obra teoría alguna sobre la verdad, sino más bien la indicación de que no cabe ningun $\mathrm{a}^{11}$. Sin embargo, por mor del argumento, como se suele decir, daré por

9. Las dificultades, probablemente insalvables, con las que todo intérprete de Nietzsche ha de enfrentarse en relación con este asunto, han sido puestas de relieve por Westphal 1984.

10. El primer tipo de "salvación" lo encontramos, por ejemplo, en Kaufmann 1975, Wilcox 1982, Richardson 1996, Hales y Welshon 2000, y Stack 2005; el segundo, en Danto 1980, en Schacht 1983 —después de darle muchas vueltas, eso sí- y en Anderson 1996, 1998 y 1999; y el tercero, en Zimmerli 1999.

11. Sobre estas cuestiones es sumamente útil el detallado, y ya clásico, libro de Maudmarie Clark Nietzsche on Truth and Philosophy (1990). Clark adopta una posición original y rigurosamente argumentada, aunque no exenta de dificultades y demasiado conservadora para el gusto de muchos nietzscheanos actuales. De acuerdo con Clark, Nietzsche habría defendido a lo largo de su vida dos visiones diferentes acerca de la verdad. En la primera fase (en la que habría que incluir Sobre verdad y mentira en sentido extramoral y Humano, demasiado humano), Nietzsche acepta la teoría de la verdad como correspondencia y la posibilidad de la cosa-en-sí, aunque sólo sea en el sentido débil de que existe un mundo independiente de nuestra experiencia. Ahora bien, como cree imposible la correspondencia de nuestros juicios con la cosa-en-sí, concluye entonces que toda verdad es una 
sentado que Nietzsche puede escapar a la acusación de inconsistencia y me restringiré, como ya señalé antes, al análisis de su argumentación contra el realismo. Volviendo, pues, a nuestro asunto, ¿̇usó realmente Nietzsche el argumento que Stove designó como el peor argumento del mundo? Si hemos de hacer caso a algunos de sus comentaristas, parece ser que así fue. El siguiente texto de George Stack (2005: 191) es casi una paráfrasis de dicho argumento:

A lo largo de sus escritos Nietzsche repite un estribillo: sólo conocemos lo que ha sido filtrado a través de nuestros selectivos sentidos, clasificado mediante nuestro

ilusión. Lo que esto quiere decir entonces es que cualquier pretensión de establecer una correspondencia entre nuestros juicios y las cosas tal y como son con independencia de nuestra experiencia está condenada al fracaso. Esta posición, sin embargo, termina mostrándose como inconsistente y Nietzsche la abandona. En la segunda fase (a partir de La genealogía de la moral) Nietzsche considera que la noción de cosa-en-sí es contradictoria, pero al mismo tiempo admite que hay algunas verdades y que, por tanto, no toda verdad es una ilusión. Evidentemente esto implica que ya no puede entender la verdad como una correspondencia con las cosas-en-sí («verdad metafísica» según la denominación de Clark). No obstante, Nietzsche aceptaría en este segundo momento — siempre según Clark— la «versión de sentido común» o «mínima» de la verdad como correspondencia. Según esta versión, la verdad consiste en la correspondencia de nuestros enunciados, juicios, creencias, etc., con un mundo que es independiente de nuestras representaciones de él, pero cualquier consideración sobre el carácter de este mundo como cosa-en-sí es ajena a esta versión y huelga por completo.

La interpretación de Clark, sin embargo, no encaja bien, tal como ella reconoce, con dos obras de transición entre una fase y otra, La gaya ciencia y Más allá del bien y del mal. En ellas Nietzsche rechaza ya la cosa-en-sí como contradictoria o inconcebible (por ejemplo, en FW $\mathbb{3} 354$ y en JGB $\$ 16$ ), pero mantiene todavía la tesis de la falsificación de la realidad, esto es, que nuestras representaciones sólo nos proporcionan errores, falsedades. Son sólo mentiras útiles. Esta combinación parece difícilmente encajable, pues, si no hay un «mundo verdadero», una cosa-en-sí, ċcon respecto a qué se consideran ahora errores o falsedades todas nuestras verdades? La tesis de la falsificación parece exigir la aceptación correspondiente de un «mundo verdadero» con respecto al cual nuestras creencias están falseadas. Para explicar esta pervivencia de la tesis de la falsificación cuando ya ha rechazado la noción de cosa-en-sí, Clark acude al influjo que tenía aún sobre Nietzsche la teoría schopenhaueriana de que el objeto de nuestro conocimiento son nuestras representaciones y no una realidad independiente. Nuestras representaciones imponen un orden a priori, una estructura, una simplificación y selección al «caos de las sensaciones», el cual constituiría entonces la única realidad, pero no un «mundo verdadero» o una cosa-en-sí. En tal sentido, nuestras representaciones dotan a este caos de rasgos que no posee y, por tanto, lo falsifican.

Las tesis de Clark no han convencido, sin embargo, a buena parte de los intérpretes de Nietzsche, para los cuales éste habría mantenido siempre la tesis de la falsificación (toda «verdad» es un error o ilusión). Una crítica de dichas tesis puede encontrarse en Lanier Anderson 1996 y 1999, y Hales y Welshon 2000: 28-31. No obstante, si Clark tuviera razón, tanto la acusación de inconsistencia (Principio Ismael) como la de la presunta utilización del peor argumento del mundo, quedarían restringidas al primer Nietzsche, pues el segundo, al rechazar la tesis de la falsificación, no sostendría que no podemos conocer las cosas y aceptaría que hay al menos algunas verdades sobre el mundo.

Tampoco habría mucho más que objetar desde un punto de vista realista a la posición de Nietzsche si tiene razón Babich 1999: 7 cuando escribe: "Cuando Nietzsche habla acerca de la verdad no se evade, como muchos filósofos contemporáneos se inclinan hoy a hacer, invocando una pseudoconcepción de la verdad, o una concepción aguada, o 'débil'. La verdad para Nietzsche (la verdad que él afirma que no existe) es la verdad exactamente platónica, o ideal, noumenal, o última». Si, como pretenden algunos intérpretes — pensando que así ofrecen un retrato más crítico de la tradición filosófica-, lo que Nietzsche quiere decir es únicamente que no existen verdades últimas, absolutas, incondiconadas; correspondencias con un mundo platónico, inmutable y trascendente, pocos filósofos contemporáneos, incluyendo entre ellos a todos los realistas de relevancia, le llevarían la contraria. No obstante, la lectura más habitual de Nietzsche interpreta sus tesis de forma más radical, lo que permite que tenga sentido seguir con estas reflexiones. 
esquema categorial, enmarcado por nuestro lenguaje, conformado por nuestra psicología y nuestras necesidades instrumentales. Conocemos los fenómenos o «efectos» en tanto que constituidos, en numerosos aspectos, por nosotros mismos. Sin embargo, el ámbito de las apariencias fenoménicas no es nuestra creación (como lo es en el idealismo): «no somos nosotros solamente la causa» de que tales fenómenos aparezcan [...]. Los fenómenos del «mundo externo», que encontramos como «obstáculos» o resistencias y que son objetos de los que llegamos a ser conscientes, son «la suma de las restricciones [Hemmungen] experimentadas» [...]. A lo largo de su vida intelectual Nietzsche caracteriza consistentemente el proceso de conocer como si implicara una imposición a las cosas de una falsa identidad, simplificación, asimilación, organización y esquematización. Si el conocimiento es consecuencia de las actividades constitutivas y sintéticas de la percepción sensorial, implica entonces la "humanización» de algo, incorporarlo dentro de esquemas familiares, apropiárselo y trasmutarlo.

Y otra acreditada intérprete de Nietzsche, Babette Babich (1999a: 6), se expresa en términos similares, aunque algo más oscuros:

Nos esforzamos por una aprehensión nouménica — conocimiento puro, forma pura- de la «cosa en sí», pero todo lo que captamos - y todo lo que podemos captar- en una aprehensión conceptual o perceptual, por muy precisa y refinada que sea, nunca es la esencia de la aprehensión ideal, sino siempre y sólo eben diese Welt. Sin embargo, para Nietzsche, por mucho que deseemos conocer el mundo aparte de las constricciones o de las redes de nuestros esquemas conceptuales o de la contingencia de la apariencia evanescente, el único mundo alcanzable en nuestra búsqueda de la permanencia es una voluntad de vestigio.

Nadie puede capturar la realidad: ésta es la hazaña y la belleza (arte) del lenguaje, si bien es también el juicio del tiempo. Para Nietzsche, tomado con exactitud, esto significa que nuestros términos son aprehensiones imprecisas de aquello a lo que se dirigen (intended): no tocan, ni pueden tocar al objeto individual o cosa.

Hay quien va más allá y cree que «la posición de Nietzsche es mucho más radical que cualquier argumento que sostenga que los seres humanos no somos capaces de captar la realidad porque estamos involucrados en nuestra propia actividad interpretativa» (Herrmann-Pillath 1993: 37). No se trataría, según esto, de que el sujeto cognoscente estuviera impedido para alcanzar con su conocimiento las cosas tal como son debido a que entre ellos se interponen los medios cognitivos habituales e imprescindibles, se trataría más bien de que sólo hay interpretaciones, y, por tanto, sujeto cognoscente, objeto conocido, cosas permanentes, etc. no son en última instancia más que creaciones, interpretaciones nuestras. De modo que «la idea de 'realidad' se disuelve en la idea del mundo como la completa interacción de actividades interpretativas, no la totalidad de 'las cosas' que estas actividades interpretan» (ibid.). En todo caso, el resultado viene a ser el mismo: Nietzsche rechaza la idea de un conocimiento de la realidad y pone en su lugar un conjunto de interpretaciones, todas ellas, por cierto, falsas, o por decirlo de forma menos tajante, todas ellas sujetas a distintos grados de ilusión.

En lo que sigue, intentaré mostrar que al menos uno de los puntales principales de la tesis de la falsificación de Nietzsche está en su epistemología evolucionista, pero, precisamente por ello, esta tesis carece de una fundamentación 
adecuada, ya que desde consideraciones evolucionistas no hay bases para sustentar el ficcionalismo de Nietzsche y, por tanto, que el argumento implicado en su desarrollo es una modalidad de «la Joya». Y si bien este argumento no es la única vía que Nietzsche emplea para sustentar su antirrealismo, sí es la principal.

\section{LA EPISTEMOLOGÍA EVOLUCIONISTA DE NIETZSCHE}

Nietzsche encajaría bastante bien en algunos enfoques recientes en epistemología, y probablemente no mejor en los que más acordes se consideran a sí mismos con su pensamiento. Como ha señalado C. U. M. Smith (1987), Nietzsche estuvo muy influido por el neokantismo y por ciertos desarrollos de la fisiología de la percepción. Desde ambos lados se concluía que la mente tiene un papel activo en el proceso de conocimiento y no se limita a ser un simple receptáculo vacío. En la medida en que Nietzsche hizo suya esta idea y consideró relevante para defenderla la apelación a una ciencia empírica como la fisiología, su posición se asemeja enormemente a lo que se conoce actualmente como epistemología naturalizada. Y, de hecho, como es ya bien sabido, Nietzsche puede ser considerado como uno de los antecedentes más claros de la actual epistemología evolucionista. Siempre consideró al ser humano desde una perspectiva naturalista, como un cierto tipo de animal que debe ser entendido en el contexto de su desarrollo evolutivo, incluyendo en ello sus facultades cognitivas, su inteligencia. Eso le llevó por caminos filosóficos contrarios a los prevalecientes en la tradición filosófica. Smith (1987: 87) llega a afirmar un tanto entusiásticamente que «sólo con Nietzsche todo el significado filosófico del pensamiento evolucionista consigue abrirse paso para afectar a las bases de la metafísica europea». Es quizás en el muy citado comienzo de Humano, demasiado humano $(\mathbb{S} 2)$ donde se expone de forma más directa esta profesión de fe evolucionista:

Defecto hereditario de los filósofos. - Todos los filósofos comparten el defecto de partir del hombre actual y creer que han llegado a su objetivo mediante un análisis del mismo. Instintivamente conciben al «hombre» como una aeterna veritas, como un invariable en todos los torbellinos, como una medida segura de las cosas. Pero todo lo que el filósofo afirma sobre el hombre no es en el fondo más que un testimonio sobre los hombres de un espacio de tiempo muy limitado. La falta de sentido histórico es el defecto hereditario de todos los filósofos; muchos incluso toman sin darse cuenta la forma más reciente de hombre, tal como resulta bajo el efecto de determinadas religiones y de determinados acontecimientos políticos, como la forma fija de la que se debe partir. No quieren saber que el hombre se ha desarrollado (geworden), que la capacidad de conocer se ha desarrollado; mientras que algunos de ellos pueden extraer el mundo entero a partir de esa capacidad de conocer. Ahora bien, todo lo esencial de la evolución humana sucedió en tiempos remotos, mucho antes de esos cuatro mil años que conocemos aproximadamente. En estos años el hombre no puede haber cambiado mucho.

La epistemología evolucionista, precisamente, es aquella rama del naturalismo epistemológico que considera que la ciencia empírica más relevante para alcanzar consecuencias sobre el origen y función de nuestras capacidades cognitivas es la biología evolucionista (en conjunción, cuando sea oportuno, con otras ciencias, como la psicología, la neurofisiología, la lingüística, la antropo- 
logía, etc.). Como escribe Franz Wuketits, uno de sus más afamados defensores (1990: ix): «El supuesto básico de la epistemología evolucionista es que los humanos, como otros seres vivos, son el resultado de procesos evolutivos y que, en consecuencia, sus capacidades mentales están constreñidas por los mecanismos de la evolución biológica».

Esto no significa que Nietzsche asumiera por completo la teoría de Darwin, ni siquiera que la entendiera correctamente. Aunque hay bastantes similitudes entre sus planteamientos - C. U. M. Smith (1987) dice de él que fue el primer gran filósofo en reaccionar ante la revolución darwiniana, así como Descartes lo fue en reaccionar ante la galileana, y, lo que es más, que era un darwinista sin saberlo-, lo cierto es que Nietzsche sólo conocía la teoría de Darwin de forma muy insuficiente, de segunda mano; fundamentalmente a través de la obra de Eduard von Hartmannn Wahrheit und Irrtum im Darwinismus, de la de Friedrich Lange Geschichte des Materialismus, y de las de varios opositores al darwinismo (cf. Brobjer 2004). Eso explica en buena medida que lo malinterpretara en algunas de sus críticas (por ejemplo, en los Fragmentos póstumos, KSA XIII 14[123] y [133]) ${ }^{12}$. El evolucionismo de Nietzsche estaba, desde luego, más cercano al predominante en la Naturphilosophie del Romanticismo alemán que al de Darwin.

Nietzsche asume que «la ley de la evolución [...] es la ley de la selección» $(A C \sqrt{ }$ 7), pero no interpreta la selección natural darwiniana como la supervivencia de los más aptos, sino de los más fuertes y más dotados, entendiendo además que Darwin ve como resultado de este proceso un progreso constante de las especies biológicas. En contra de esto, Nietzsche cree que el resultado de la evolución es la homogeneización de la población en torno a los mediocres, la eliminación de las excepciones, de los individuos superiores. Por eso, se muestra a veces escéptico acerca de que "los organismos superiores hayan evolucionado a partir de los inferiores» (KSA XIII 14[123]). Cree además que las especies tienden a conservar el tipo propio, sin que el cambio de ambiente produzca cambios radicales en ellas: «Cada tipo tiene sus límites más allá de los cuales no hay evolución» (KSA XIII 14[133]). De ahí que no encontremos formas de transición entre las distintas especies. Y no cree, por otro lado, que las variaciones accidentales puedan producir por sí mismas una ventaja durante un tiempo suficiente a los organismos. En La genealogía de la moral (II, \$12) considera que la adaptación de los organismos a su entorno es, comparada con la voluntad de poder, una fuerza secundaria en lo que se refiere a la creación de nuevas posibilidades, direcciones y formas vitales. La voluntad de poder sería una fuerza interna, espontánea, que subyace a todas las funciones de los organismos y las dirige. Una fuerza que actuaría, pues, como motor de todo el proceso evolutivo y que Nietzsche termina identificando como fuerza fundamental del Universo, incluidos los fenómenos puramente físicos y químicos. En la segunda edición de La gaya ciencia (\$349) y en Crepúsculo de los ídolos («Incursiones de un intempestivo», $\mathbb{S} 14$ ) afirma incluso que la lucha por la

12. Para una revisión de autores evolucionistas que fueron leídos y aprovechados por Nietzsche puede verse Zárate 2000 y, especialmente, Moore 2002. En este último queda de manifiesto la enorme importancia que tuvo en la obra de Nietzsche la biología de su tiempo - y especialmente de autores no darwinistas, como Wilhelm Roux, William Rolph y Carl von Nägeli, a los que Nietzsche debe casi todos sus errores en la interpretación de Darwin. 
supervivencia es algo excepcional y que más bien lo que se da es una lucha por el poder en una naturaleza que se muestra pródiga y superabundante en recursos. Las discrepancias con la teoría de Darwin no son menores, como puede apreciarse ${ }^{13}$. Ello ha provocado que algunos intérpretes (como Gregory Moore) califiquen la visión evolucionista de Nietzsche de anti-darwinista. En éste, como en tantos otros puntos de la filosofía nietzscheana, los desacuerdos son radicales.

Ciertamente Nietzsche no era un darwinista estricto, como, puestos a ser puntillosos, no lo era prácticamente nadie en su época, ni siquiera entre los biólogos más favorables a las tesis evolucionistas. Como es bien sabido, la obra de Darwin contribuyó a una rápida aceptación del evolucionismo, pero el papel que Darwin atribuyó al azar y a la selección natural no tuvo tan favorable acogida. Que el evolucionismo nietzscheano esté muchas veces más cerca del lamarckismo que del darwinismo no debe sorprender cuando el propio Darwin acepta la idea de los caracteres adquiridos y los elementos lamarckistas perviven en el darwinismo hasta su eliminación por August Weissman a finales del siglo xIx. Sin embargo, y sin perder de vista las discrepancias señaladas, no creo que sea exagerado decir que en lo que se refiere a la epistemología que Nietzsche elabora, la inspiración proporcionada por la teoría de Darwin resulta notoria, aunque le llegara por vías indirectas.

El interés de Nietzsche por la evolución biológica está fundamentalmente centrado en la evolución humana (cf. Moore 2002: 34) y, al fin y al cabo, hasta la obra de Darwin no encontramos una referencia tan sólida —aun cuando en el Origen de las especies se haga todavía tímidamente y al final- a la necesidad de entender el origen del propio ser humano (y, por ende, de sus capacidades cognitivas) en el contexto general de la evolución biológica. George Stack (2005: 147) lo hace notar sin rodeos cuando afirma que «a pesar de discrepancias ocasionales con algunas de las opiniones de Darwin — particularmente que el objetivo de

13. Sin embargo, como el lector informado reconocerá, ni la homogeneización de las poblaciones en ciertas circunstancias en torno a rasgos intermedios (selección estabilizadora), ni el fenómeno de la gran estabilidad de las especies durante la mayor parte de su historia evolutiva - lo cual explicaría la escasez de hallazgos de formas transicionales - son hechos desconocidos para el darwinismo actual. Pero los elementos antidarwinistas de Nietzsche son claros y explícitamente señalados por él mismo. Por eso, a C. U. M. Smith, se le va decididamente la mano cuando afirma que «el concepto de Nietzsche de la voluntad de poder era similar a la idea darwiniana de la lucha de los individuos por la supervivencia» (Smith 1987: 75). Precisamente, si hay un elemento claramente contrario a la doctrina de Darwin es la tesis nietzscheana de la voluntad de poder como una fuerza interna conductora de los cambios en los organismos. Una fuerza de este tipo es un ejemplo de lo que Daniel Dennett llama "ganchos celestes» (skyhooks), es decir, hipótesis poco fundamentadas que intentan dar una explicación de la evolución a modo de ascensores teóricos — «colgados del cielo», podríamos decir- que apelan a procesos complejos capaces de dirigirla eficazmente. Frente a ellas estarían las «grúas» (cranes), que serían hipótesis que buscan explicar la evolución desde procesos más básicos y graduales — «sustentados en el suelo», por seguir con el símil- en los que cada paso sería una transformación algorítmica a partir del anterior. Para Dennett, la selección natural sería un ejemplo de grúa mientras que la voluntad de poder, como hemos dicho, sería un ejemplo de gancho celeste (cf. Dennett 1995: 461-467 y, para un comentario sobre esta cuestión, Nola 2003: 478-481). En tal sentido, y contrariamente a lo que sostiene Cox (1999: 6), la voluntad de poder tiene muy poco que ver con las entidades teóricas, como los quarks, postuladas por las ciencias empíricas. Y aunque, como afirma Herman-Pillath (1993), presenta ciertas similitudes con la teoría sistémica de la evolución, es difícil esquivar los argumentos de Dennett que la muestran como incompatible con el darwinismo. 
los seres orgánicos sea la preservación en lugar de la expresión de energía y el aumento de su 'poder'- Nietzsche, en general, construye su epistemología evolucionista con ladrillos darwinianos».

En consonancia con este enfoque naturalista, Nietzsche considera que el conocimiento tiene fundamentalmente una función biológica, de ahí que esté sujeto a un proceso evolutivo. El conocimiento humano en concreto -al que hay que considerar siempre en estricta contigüidad con el de otros organismossólo puede ser cabalmente entendido en el contexto de su utilidad para la vida, de su valor para la supervivencia de nuestra especie. "Todos nuestros órganos de conocimiento y nuestros sentidos —escribe en sus notas- son desarrollados (entwickelt) sólo con vistas a condiciones de conservación y crecimiento» (KSA XII 9[38]). Es necesario, por tanto, dar una explicación naturalista de nuestras capacidades cognitivas. Pero Nietzsche insiste en que esa función biológica de supervivencia es la primada por la evolución, y no la verdad o correspondencia de nuestras creencias con una supuesta realidad objetiva; algo que desde el punto de vista de la evolución biológica sería por completo indiferente. De ahí que juzgue todos nuestros conocimientos como errores que han resultado útiles para la supervivencia de la especie humana:

A lo largo de periodos enormes el intelecto no ha engendrado más que errores, algunos de los cuales resultaron provechosos y ayudaron a conservar la especie. El que dio con ellos, o los recibió en herencia, luchó con mayor fortuna la lucha por él mismo y por su descendencia. Tales dogmas erróneos, que siempre se volvían a heredar y que finalmente se convirtieron en elementos fundamentales y específicos del ser humano, son por ejemplo los siguientes: que hay cosas permanentes; que hay cosas iguales; que hay cosas, materias, cuerpos; que una cosa es aquello que parece; que nuestro querer es libre; que lo que es bueno para mí es bueno en sí y por sí (FW $\mathbb{S} 110)$.

Es importante señalar que — tal como se pone de manifiesto en esta citaNietzsche no sólo atribuye un valor biológico a nuestras capacidades cognitivas, sino, lo que es más controvertido desde el punto de vista de la epistemología evolucionista actual, al contenido de nuestras creencias. No son sólo nuestros órganos de conocimiento, sino nuestras mismas convicciones fundamentales acerca del mundo las que pueden encontrar un origen evolutivo.

Las convicciones metafísicas fundamentales, que forman parte del sentido común, la existencia de cuerpos que perduran en el tiempo, la igualdad entre algunos de estos cuerpos materiales, la no coincidencia exacta entre lo que percibimos y lo que las cosas son, el libre albedrío, etc., son, según Nietzsche, creencias falsas pero que, pese a ello, o quizás sería mejor decir, precisamente por ello, han permitido que estemos aquí como especie biológica. Nos han ayudado incesantemente en la lucha por la supervivencia. Nos han permitido estructurar el caos de nuestras sensaciones dotándole de un orden ficticio pero adecuado para el manejo y el control de los procesos naturales.

Sin la construcción de objetos permanentes e iguales, sin la fijación y estructuración de lo móvil y puramente fluyente, no habríamos podido sobrevivir como especie (y es de suponer que Nietzsche habría estado dispuesto a atribuir esto mismo a otros animales si hubiera sabido que son capaces de forjar una cierta representación mental de la permanencia objetual). Por lo tanto, la evolución 
nos ha preparado para aceptar tales convicciones como verdaderas. Necesitamos creer en un mundo estable y estructurado:

¿De dónde surge la lógica en la cabeza humana? Seguramente de lo ilógico, cuyo imperio debió ser inmenso originariamente. Pero innumerables seres que inferían de forma distinta a como lo hacemos nosotros ahora, habrán sucumbido: isiempre podría haber sido más verdadero! Quien, por ejemplo, no supo encontrar con la frecuencia suficiente lo «igual» respecto de la alimentación o al animal enemigo, quien fuera así demasiado lento para subsumir, demasiado cuidadoso en la subsunción, tenía menores probabilidades de seguir viviendo que quien en todo lo semejante adivinara la igualdad. Pero esta disposición preponderante a tratar lo semejante como igual —una disposición ilógica, pues no hay en sí cosas igualeses la que ha generado todos los fundamentos de la lógica (FW \$111).

Nietzsche sostiene que el mundo es un puro devenir caótico, un flujo perpetuo en el que nada hay que pueda ser considerado como «ser», en el que nada conserva una identidad a través del tiempo. Sin embargo, creer que hay seres, objetos permanentes, causas y efectos, permite a los seres humanos ordenar ese caos de forma útil para sus propósitos. Ese orden es un orden ficticio, pero necesario para la vida. En un punto Nietzsche parece coincidir con algunos realistas actuales que defienden el realismo desde bases evolucionistas: creer que hay leones o conejos que son independientes de nuestra mente, que existen mientras no los percibimos y que pueden ser la causa de nuestra muerte o de nuestra buena alimentación es más adaptativo que mantener una posición escéptica al respecto, porque permite huir de los leones y cazar conejos, incluso cuando se esconden y dejamos de verlos. La diferencia es que mientras los defensores del realismo concluyen de ahí la verdad del realismo, al menos de forma hipotética, esto es, concluyen que hay objetos independientes de nuestra mente que son aproximadamente tal y como nos lo representamos, y de ahí el éxito de estas creencias, Nietzsche concluye que la evolución nos ha llevado a construir un mundo completamente ficticio enfocado sólo a nuestra supervivencia, porque objetos y causas son productos de nuestro lenguaje, no cosas del mundo. El éxito de estas creencias no radica, pues, en su correspondencia con la realidad. Simplemente, para Nietzsche, este éxito es un hecho bruto ${ }^{14}$ :

14. El contraste puede apreciarse en la conclusión, contraria a la de Nietzsche, que Nicholas Rescher (1990: 64) saca del origen evolutivo de nuestras capacidades cognitivas: «Esto significa que la naturaleza debe ser cooperadora en un cierto y particular modo; debe ser suficientemente estable, regular y estructurada como para que haya respuestas apropiadas a los eventos naturales que puedan ser «aprendidas» por las criaturas. [...] Un entorno orgánicamente viable - y no digamos uno cognoscible- ha de incorporar estructuras experienciables». Pero el contraste es más explícito aún si atendemos a las palabras de uno de los padres del enfoque evolutivo de la cognición, Konrad Lorenz (1989: 19-20): «Los 'anteojos' de nuestras formas de pensar y ver, como causalidad, sustancia, espacio y tiempo, son funciones de una organización neurosensorial, surgida al servicio de la conservación de la especie. A través de esos anteojos no vemos, pues, como suponen los idealistas trascendentales, una deformación imprevisible del ser-en-sí —la cual no presenta ni la más vaga analogía, ni relación icónica alguna con la realidad—, sino una imagen real de esa misma realidad, aunque sea una imagen radicalmente simplificada por fines utilitaristas: nosotros sólo hemos desarrollado un 'órgano' para aquellos aspectos del 'ser-en-sí' con los que el establecimiento de una relación utilitaria era de tan vital importancia para la conservación de la especie, como para que una adecuada presión selectiva produjese la formación de ese aparato especial de conocimiento». 
En tiempos pasados se tomaba la transformación, el cambio, el devenir en general como prueba de apariencia, como signo de que ahí tenía que haber algo que nos llevara al error. Hoy, por el contrario, en la medida en que el prejuicio de la razón nos obliga a atribuir unidad, identidad, duración, sustancia, causa, coseidad, ser, nos vemos en cierto modo enredados en el error, necesitados del error; por muy seguros que estemos basándonos en una rigurosa comprobación de que es ahí donde está el error. Sucede con esto lo mismo que con los movimientos de los grandes astros: aquí el error tiene como abogado permanente a nuestros ojos, allí a nuestro lenguaje (GD, «La 'razón' en la filosofía», $\mathbb{S}$ ).

Y en otro lugar añade: "La verdad es la clase de error sin el que no puede vivir un ser viviente de una determinada clase. El valor para la vida es lo que decide en último término» (KSA XI 34[253]).

Todo esto quiere decir que, para Nietzsche, y a diferencia de lo que sostendría un realista popperiano, estos errores son ineliminables, incluso una vez detectados. No podemos hacer nada por eliminar el error. Eso sería tanto como pretender ir contra lo que nos permite sobrevivir. «El intento de eliminar toda perspectiva e interpretación para alcanzar 'los hechos' —aclara Christoph Cox (1999: 44) — es [...] no sólo imposible sino deplorable; pues, en esencia, no es otra cosa sino el rechazo de la naturaleza y la vida, para las cuales todo conocimiento es perspectivo o interpretativo e implica así [...] engaños 'extramorales'».

En este empeño en mantener la inevitabilidad del error para garantizar la propia existencia Nietzsche se separa de una parte significativa de los cultivadores actuales de la epistemología evolucionista. Precisamente, el origen evolutivo de nuestras capacidades cognitivas ha sido utilizado por algunos para explicar la fiabilidad de éstas, es decir, su tendencia a producir creencias verdaderas (cf. Goldman 1990) ${ }^{15}$. Cabe incluso aceptar que capacidades cognitivas por lo general fiables pueden dar lugar en ocasiones a ciertas creencias falsas con valor adaptativo y que, por tanto, no puede inferirse sin más la verdad de una creencia a partir del supuesto de que fue útil para la supervivencia. La naturaleza, desde el punto de vista de la evolución, es hasta cierto punto «tolerante al error» (cf. Rescher 1990: 72-73). Un buen ejemplo lo proporciona la psicología del asco (cf. Diéguez 2002). El asco nos hace evitar en ocasiones —erróneamente- alimentos nutritivos, en la creencia de que no son aceptables para nuestro organismo. Sin embargo, puede ser considerado como un sentimiento con valor

15. Lo cual, por cierto, no lleva necesariamente a comprometerse con ningún sentido absoluto o «metafísico» de verdad, ni con ningún «mundo verdadero» al estilo platónico, o mundo nouménico al estilo kantiano. Franz Wuketits ha ejercido en este asunto como buen portavoz de los que así piensan: «Me apresuro a decir que ningún abogado de la epistemología evolucionista sostendría que la cosa-en-sí (sea esto lo que sea) es perceptible por nosotros o por cualquier otro ser vivo; ni argüiría ningún epistemólogo evolucionista que vemos (nosotros u otros seres vivos), oímos, etc., todos los aspectos de la realidad. Pero los epistemólogos evolucionistas de hecho afirman que, primero, las estructuras del mundo externo son reales y no mero producto de nuestra imaginación (de modo que existen incluso cuando no son percibidas), y, segundo, que la realidad es perceptible (cognoscible) al menos en parte. La correspondencia entre un organismo y su mundo externo es una consecuencia lógica de la teoría de la evolución orgánica. Pero esta correspondencia no significa necesariamente que la imagen (de partes) del mundo que un organismo tenga sea perfecta. Ellos —o, sería mejor decir, muchos de ellos- defienden un tipo de realismo que ha sido denominado realismo hipotético» (Wuketits 1990: 76). Para una crítica de las posiciones que pretenden defender el realismo desde planteamientos evolucionistas puede verse Wilson 1990, Stich 1990 y 1994, y Thomson 1995. 
adaptativo, ya que ha permitido que evitemos a lo largo de nuestra historia evolutiva alimentos auténticamente peligrosos o nocivos. En esto de la sospecha ante los alimentos, como señala Stephen Stich (1994: 347), «la selección natural puede muy bien preferir una estrategia inferencial extremadamente cauta y que a menudo resulte falsa a una estrategia menos cauta pero que permita obtener con más frecuencia la respuesta correcta». Pero Nietzsche no habla aquí de errores ocasionales que impedirían inferir la verdad de ciertas creencias a partir de su valor adaptativo. Nietzsche aparentemente habla de un error masivo. Todas nuestras creencias fundamentales serían erróneas, construcciones ficticias. Ahora bien, una cosa es que el éxito para la supervivencia no justifique la verdad de las creencias y otra muy distinta que el error masivo sea compatible con la supervivencia.

Si admitimos que muchas de nuestras creencias son falsas aun cuando puedan ser útiles para la supervivencia, como hacen algunos críticos del realismo, entonces podemos concluir que, en efecto, nuestras capacidades cognitivas no están adaptadas para proporcionar creencias verdaderas, sino creencias apropiadas para asegurar la supervivencia y la reproducción, sean éstas verdaderas o falsas. Ahora bien, si todas nuestras creencias fundamentales sobre el mundo son falsas, entonces no se trata sólo de que nuestras capacidades cognitivas no hallan sido seleccionadas por generar verdades; es algo mucho más radical: es que carecen de toda fiabilidad; y en tal caso, es difícil entender cómo han podido ser seleccionadas, dado que precisamente su función es la de conocer el entorno. ¿Cómo puede ayudar a la supervivencia el que todas nuestras creencias sean meramente ilusiones y errores? ¿Cómo puede ayudar a la supervivencia el que veamos objetos, o causas y efectos, donde no hay tales cosas, donde no hay más que un devenir desestructurado? ¿Cómo puede sernos útil un orden impuesto por nosotros al mundo, pero del que éste mismo carece por completo? ¿Por qué en un mundo en total devenir iba a tener mayor valor para la supervivencia la creencia en objetos perdurables que una visión, todo lo incompleta que se quiera, pero más ajustada, de ese flujo? ¿Es siquiera posible concebir el surgimiento de la vida y su evolución en un mundo carente de cualquier orden previo? Nietzsche no se plantea este tipo de preguntas y, por tanto, no hay en su obra una respuesta satisfactoria para ellas.

Pero Nietzsche no puede ser culpado por no coincidir con los realistas evolucionistas de nuestros días. De hecho, se ha criticado repetidamente en las últimas décadas el intento de basar el realismo en la evolución de nuestras capacidades cognitivas. Se ha afirmado que lo más que se puede decir sobre el conocimiento desde un punto de vista evolucionista es que, en el nicho ecológico que ocupamos, el conocimiento no es inmediatamente destructivo (cf. O'Hear 1984: 212). Habría, pues, mucho que decir y matizar en esta cuestión ${ }^{16}$. No obstante, si se acepta este argumento contra el realismo evolucionista, lo mismo podría decirse entonces del intento de Nietzsche y de otros de rechazar el realismo sobre bases evolucionistas. No se ve por qué el antirrealista sí podría sacar ventaja aquí, mientras que el realista no. Si del hecho de que el conocimiento nos facilita, o al menos no nos impide, la adaptación a nuestro nicho biológico no puede concluirse sin más que todos los productos del conocimiento sean verdaderos en el

16. A tal efecto, puede verse a modo de introducción Diéguez 2002. 
sentido de la verdad como correspondencia (y esto es algo que la mayor parte de los realistas concedería de buen grado), menos aún parece que pueda concluirse que sean falsos (en el sentido que sea). En resumen, del éxito práctico de nuestras representaciones del mundo no cabe concluir sin más la verdad de las mismas, como ha quedado bien establecido en el debate contemporáneo sobre el realismo, pero menos razones aún parece haber para concluir su falsedad.

\section{PERSPECTIVISMO Y FALSIFICACIÓN}

La posición de Nietzsche acerca de nuestro conocimiento del mundo es usualmente designada como "perspectivismo». Según Nietzsche, sólo hay diferentes perspectivas sobre el mundo, y no sólo individuales o relativas a ciertos esquemas conceptuales o «juegos de lenguaje», sino relativas también a la especie (cf. WL). El conocimiento es siempre aproximación a la realidad desde una perspectiva concreta, es, pues, algo irreductiblemente múltiple y diverso.

Existe sólo un ver perspectivista, sólo un «conocer» perspectivista; y cuantos más afectos sobre una cosa dejemos llegar a las palabras, cuantos más ojos, ojos distintos, nos sepamos colocar para la misma cosa, tanto más completo será nuestro «concepto» de esa cosa, nuestra «objetividad» (GM III, $\mathbb{S} 12$ ).

Las diferentes perspectivas no nos proporcionan una parte de la verdad, sino únicamente una interpretación posible de la realidad entre otras muchas. Ni siquiera la unión de diferentes perspectivas nos llevaría a un acercamiento mayor a la verdad. Sólo equivaldría a la yuxtaposición de interpretaciones, lo cual no siempre puede hacerse coherentemente. Lo más que cabe decir, como deja ver la cita anterior, es que cuantas más perspectivas seamos capaces de emplear, más completa será nuestra visión de las cosas, pero no más verdadera. Esa «objetividad» entre comillas de la que habla aquí Nietzsche no se refiere, claro está, a las cosas tal como son en sí mismas, sino precisamente a la complementación de las diferentes perspectivas. Esa «objetividad» no es sino la asunción de la irreductible pluralidad de enfoques. El sustento de toda interpretación es el aumento de a voluntad de poder y, con ello, la promoción de la vida. Por tanto, hemos de jugar con las diferentes perspectivas, con las distintas interpretaciones, como si ésta fuera la mejor estrategia para la vida. Como señala A. D. Schrift, «puesto que la vida es una multiplicidad enigmática que ha de ser dominada, puesto que no hay 'límites a los modos en que el mundo puede ser interpretado', necesitamos un enfoque interpretativo que nos permita experimentar con una pluralidad de perspectivas» (Schrift 1985: 394) ${ }^{17}$.

17. No obstante, proponer la afirmación de la vida como criterio de juicio o de evaluación de las interpretaciones, como hace Schrift (1985: 394), nos lleva de nuevo al problema de si tal cosa puede hacerse compatible con la tesis de la falsificación. Pretender que se puede decidir objetivamente que una interpretación cumple ese fin mejor que otra sería aceptar como verdadero al menos un enunciado, a saber, «tal representación favorece la vida». Es obvio, sin embargo, que un juicio así, desde la filosofía nietzscheana, no puede ser una verdad objetiva, sino una interpretación más. En general, el planteamiento epistemológico de Nietzsche, no puede evitar el problema ya señalado de la autorreferencia. Si se afirma que lo que llamamos «verdades» son sólo cierto tipo de errores útiles 
Pero la cuestión que suscitábamos antes permanece. ¿Por qué habla Nietzsche aquí de «errores»? ¿Presupone esto que hay verdades sobre el mundo, solo que el ser humano, por alguna extraña razón, no las alcanza nunca, y puede, sin embargo, vivir muy bien con ciertas falsedades? ¿O lo hace tal vez para mostrar que la distinción entre error y verdad, entre apariencia y realidad, es una distinción rechazable?

Es difícil aceptar que el uso repetido a lo largo de los años de estas expresiones tan radicales tuviera una función meramente retórica, sólo para realzar como modelo filosófico una actitud artística, creativa, pluralista y flexible, abierta a la multiplicidad de perspectivas, frente a la actitud metafísica o a la científica, supuestamente absolutista y excluyente. ¿Habría hecho falta para ello sostener que toda verdad es una ilusión? Christoph Cox (1999: 66 y 88-89) afirma que, en efecto, el uso en este contexto de términos como «mentira», «engaño» y «error» por parte de Nietzsche es la expresión de su oposición a la pretensión platónica y positivista de alcanzar verdades absolutas, con la consiguiente minusvaloración del arte que porta esta pretensión. Pero con esta polémica ponderación — podría después de todo haberse limitado a hablar sólo de simplificación, de idealización, de visión parcial- Nietzsche quiere, según Cox, resaltar dos cosas. En primer lugar que lo que la metafísica pone como «mundo verdadero», a partir del cual se sigue el mundo de las apariencias, es más bien una «mentira» obtenida a partir del único mundo verdadero que hay, el mundo sensible, que es el que la metafísica considera como mundo de la apariencia. Y, en segundo lugar, que esas supuestas verdades son el resultado del uso de un lenguaje que crea ficciones útiles, mientras que nuestra razón nos lleva mucho más allá y nos persuade de que dependen de la propia naturaleza de las cosas.

Según Nietzsche, el lenguaje simplifica la realidad; unifica y congela un mundo que es diverso, complejo, y está en perpetuo flujo. Nuestro lenguaje emplea metáforas y descripciones antropomórficas que inevitablemente configuran lo que nos llega a través de los sentidos (cf. WL). Necesitamos de esas simplificaciones y ficciones para vivir. No podríamos desenvolvernos en la práctica cotidiana, en nuestras tareas más comunes, si no introdujéramos en el mundo un orden impuesto por nuestros intereses y necesidades. No sólo nuestra percepción es selectiva, sino que nuestros conceptos, al generalizar y eliminar lo particular, al igualar, al interpretar, constriñen y domestican la realidad en función de esos intereses y necesidades. Y, lo que es más, la mayor capacidad para hacer esto, para imponer orden en el input de la experiencia perceptiva, en lugar de perderse en su diversidad y multiplicidad o de demorarse en la generalización, proporciona, como hemos visto antes, una ventaja adaptativa (cf. Stack 2005: 152). Lo que llamamos 'verdades' no son más que las metáforas y las ficciones socialmente consagradas. De este modo, a través del proceso evolutivo de nuestra especie (y lo mismo podría decirse de otras), hemos creado un mundo a nuestra medida; a la medida de nuestras necesidades fundamentales y de nuestras capacidades cognitivas y lingüísticas, y en tal sentido, un mundo falso, o por mejor decir, falsificado.

para la vida ¿no se debe creer entonces en la verdad de la tesis de que esos errores son útiles para la vida, con lo cual habría al menos alguna verdad que no consistiría en un error útil? (cf. Nola 2003: 497-498). Así lo reconocen algunos comentaristas, como Hales y Welshon 2000: 36. 
No obstante, la atribución de falsedad a nuestras creencias más básicas sobre el mundo no debe implicar, según Nietzsche, su condena o rechazo. Por lo general, no son siquiera prescindibles, puesto que, precisamente, las creencias más falsas son las más necesarias para nuestra supervivencia:

La falsedad de un juicio no es ya para nosotros una objeción contra tal juicio; quizás sea esto lo que suene más extraño en nuestro nuevo lenguaje. La cuestión es en qué medida se trata de un juicio que favorece la vida, mantiene la vida, mantiene la especie, quizás incluso cultiva la especie. Y nosotros estamos inclinados por principio a afirmar que los juicios más falsos (entre los que están los juicios sintéticos a priori) son los más indispensables para nosotros, que el hombre no podría vivir sin admitir las ficciones lógicas, sin medir la realidad con el mundo puramente imaginado de lo incondicionado, de lo idéntico-a-sí-mismo, sin falsear permanentemente el mundo mediante el número - que renunciar a los juicios falsos sería una renuncia a la vida, una negación de la vida (JGB $\$ 4)$.

Estas afirmaciones de Nietzsche han sido interpretadas de modos diversos, según se considere su grado de radicalidad en el rechazo de las pretensiones ontológicas y epistemológicas del realismo. Pueden distinguirse actualmente al menos tres grandes líneas exegéticas acerca de la epistemología nietzscheana, que vendrían, en lo esencial, caracterizadas del siguiente modo:

1. Carece de sentido concebir el mundo como algo que existe independientemente de nuestra mente y/o nuestros lenguajes, y que es objeto de nuestras representaciones. O, por decirlo de otro modo, nuestros conocimientos, nuestros lenguajes, no nos proporcionan representaciones de un supuesto mundo independiente. "El lenguaje no es un instrumento de representación, porque en el fondo no hay nada que representar» (Schrift 1985: 374). Nuestros conceptos imponen metáforas que constituyen y crean la realidad a partir de meros estímulos nerviosos. No hay objetos discretos, ni siquiera los de sentido común; sólo un flujo de sensaciones que ordenamos inevitable pero mistificadoramente a través de nuestros conceptos y categorías. No hay nada a lo que podamos llamar de una forma neutral «verdad». Toda supuesta verdad es una ilusión que se ha olvidado de que lo es. Los hechos no existen. Lo que consideramos «hechos» no son sino interpretaciones, interminables en su variedad potencial, no sometibles a ningún criterio objetivo (incluyendo en esto la afirmación misma de que sólo hay interpretaciones). Ésta es la interpretación que hace de Nietzsche fundamentalmente un ficcionalista. Es el Nietzsche de muchos intérpretes encuadrados en eso que se conoce como "filosofía posmoderna», y quizás también, cuando va con perfiles gruesos, la caricatura presentada por algunos de sus críticos para poder despacharlo con cierta facilidad ${ }^{18}$.

2. Existe un mundo independiente de nuestras representaciones, que está en perpetuo flujo (aunque no tiene carácter nouménico o de cosa-en-sí en sentido trascendental ${ }^{19}$ ). Nuestras representaciones lo falsifican, pero en distinto grado. La metafísica platónica o el cristianismo, por ejemplo, ofrecen una falsificación de ese mundo mucho mayor que, pongamos por caso, la filosofía de Schopen-

18. Sobre los excesos de esta interpretación postmoderna es sumamente clarificador Jovanovski 2001.

19. Para los distintos sentidos de la cosa-en-sí en la obra de Nietzsche, puede verse Westphal 1984. 
hauer. En este sentido, la filosofía de Nietzsche podría considerarse como un cierto tipo de realismo, pero un realismo que pone el énfasis en el modo en que nuestros esquemas conceptuales lo distorsionan sistemáticamente (sería un misrepresentational realism, como lo denomina Richard Brown [2004: 67]). John Richardson (1996: 225), en abierto contraste con lo expresado por la cita anterior de Schrift, señala: «Nietzsche no es un nihilista [ontológico], y su argumento contra el conocimiento no es simplemente que nada puede ser conocido porque no hay nada en realidad. Más bien piensa que está en la naturaleza de la realidad el que nunca pueda ser reflejada o emparejada (matched)». En un sentido similar se manifiesta Stack (2005: 27): "La esencia de las cosas nos es desconocida, no porque esté oculta tras el velo de la cosa-en-sí, sino a causa de la actividad transformadora sensitiva, lingüística y conceptual de la 'organización' del hombre y del marco cognitivo evolucionado y heredado que sirve a su supervivencia». Las verdades que podamos formar sobre ese mundo son «falsedades» o «errores» en el sentido de que son siempre falibles, parciales, perspectivistas, simplificadoras (cf. Stack 2005: 86). Muy cerca está también la interpretación de Arthur Danto en su ya clásico Nietzsche as Philosopher (cf. Danto 1980: 96).

3. El mundo no es ni completamente independiente de la mente ni completamente dependiente. Mundo y mente se interpenetran, se codeterminan, no pueden ser separados en objetos subsistentes y representaciones pasivas de los mismos. La realidad que conocemos viene imbricada en nuestro lenguaje y nuestros conceptos, y no podemos separar lo que ponemos de lo que nos llega. Conviene, pues, eliminar de una vez por todas las dicotomías fenómeno/noúmeno y apariencia/realidad (cf. GD, «Cómo 'el mundo verdadero' acabó convirtiéndose en una fábula»). Hay sólo un mundo: el mundo del sentido común, el que percibimos por los sentidos. Hemos de aceptar, sin embargo, un relativismo ontológico: no es que no haya hechos en absoluto, es que sólo tiene sentido hablar de hechos dentro de una interpretación determinada, dentro de un esquema conceptual. Lo que no hay, pues, es un mundo pre-dado, ni hechos «brutos», ajenos a cualquier interpretación. El mundo no determina una única conceptualización o categorización. Si no tiene una estructura intrínseca, tampoco puede haber un punto de vista del ojo de Dios que lo categorice de forma total y definitiva. Diferentes esquemas conceptuales pueden proporcionar visiones viables e igualmente aceptables del mundo. Éste es el Nietzsche cercano al realismo interno que nos presentan algunos intérpretes (cf. Anderson 1998: 22 y Cox 1999: 59, 92-98 y 155-156). Para hacerlo un precedente de Putnam sólo habría que añadirle, como hace Anderson (1998 y 1999), una concepción internalista o pragmatista de la verdad. La verdad no sería una correspondencia con una realidad externa, sino el cumplimiento de ciertas normas epistémicas, de ciertas prácticas cognitivas. El pluralismo perspectivista no sería más que la expresión de un relativismo conceptual cercano al de Putnam.

Hay ciertamente en la obra de Nietzsche elementos para apoyar cualquiera de las tres y eso se debe muy posiblemente a que el propio Nietzsche oscila entre una y otra. En mi opinión la más fiel al núcleo de la obra de Nietzsche es la segunda. La primera sume a Nietzsche en las contradicciones señaladas al principio de este trabajo y lo acerca peligrosamente al idealismo que tanto rechazó, cuando no simplemente al escepticismo radical. Deja además sin fuelle —como ha explicado convincentemente Westphal (1984) - la crítica nietzscheana al cristianismo. La tercera presenta un Nietzsche privado de casi todo su mordiente 
crítico. El realismo interno mantiene que no hay una única descripción completa y verdadera de cómo es el mundo. Sólo hay descripciones parciales que pueden ser simultáneamente verdaderas aunque incompatibles. Nietzsche, como hemos visto, mantiene una tesis más fuerte: que no hay ninguna descripción verdadera (ni en sentido realista ni en sentido internalista). Además, su perspectivismo es también más radical que el del realista interno. No se trata sólo de que la ontología sea relativa a un lenguaje (o a una perspectiva). Es que esta ontología es siempre una ficción útil. El realista interno no niega la noción de objetividad, aunque, como dice Putnam, la objetividad sea siempre una objetividad "para nosotros», y considera que hay cuestiones de hecho implicadas en la determinación de si ciertos enunciados están justificados o no (cf. Putnam 1990: 21). El ficcionalismo de Nietzsche considera que cualquier pretensión de objetividad es un autoengaño, una manifestación del ideal ascético.

Sea cual sea la línea más apropiada de interpretación (con perdón de los nietzscheanos que rechazan esta misma idea), las dos primeras, que son las más difundidas, coinciden en negar la posibilidad de obtener conocimientos verdaderos acerca del mundo. Y lo hacen porque admiten que nuestras capacidades cognitivas, nuestros esquemas conceptuales, nuestros lenguajes, configuran un conjunto de creencias útiles para la vida, pero, que en el fondo, y en tanto que meros artefactos interpretativos, son falsas. Es el momento, pues, de discutir la fuerza de este argumento.

\section{NIETZSCHE Y EL PEOR ARGUMENTO DEL MUNDO}

Tomemos para empezar una distinción útil. Según sostiene Richardson (1996: 223 ss.), Nietzsche habría abierto dos frentes en su estrategia argumentativa acerca de la imposibilidad de obtener un conocimiento verdadero sobre el mundo: el frente ontológico u «objetivo» y el frente epistémico o «subjetivo». El frente ontológico consiste en argumentar que el devenir no puede ser conocido, que la realidad tiene características que la hacen incognoscible. El frente epistémico consiste en argumentar que el sujeto no puede escapar jamás de los prejuicios y limitaciones de su perspectiva, de su lenguaje.

El frente ontológico, como han señalado muchos críticos de Nietzsche, está plagado de dificultades. En especial, se enfrenta al problema ya comentado antes de la autorreferencia. Si la realidad es incognoscible, ¿cómo podemos saber que su auténtica naturaleza es el devenir? Cox (1999: 103) quiere salvar a Nietzsche de esta inconsistencia sosteniendo que el mundo como un «caos» no es presentado por Nietzsche como un hecho, como la auténtica naturaleza de la realidad, sino como una interpretación. No podía ser de otra manera, ya que todo es interpretación según Nietzsche. Una interpretación mejor que otras, eso sí, por su carácter ateológico, es decir, por ser plenamente consistente con la tesis de la muerte de Dios, por haber eliminado «la sombra de Dios». Concedamos que Cox tiene razón, y de hecho su estrategia es buena, porque hace coherente un aspecto de la filosofía de Nietzsche que parecía no serlo. Pero entonces, lo que sucede es que Nietzsche no puede presentar el carácter caótico de un mundo en perpetuo devenir como base para argüir sobre su incognoscibilidad y darla, esta vez sí, como un hecho probado. Nietzsche habría elegido sencillamente esta 
interpretación porque es la que mejor encajaría con algunas de sus otras tesis filosóficas. Estaría, pues, condicionada a la aceptación de esas otras tesis. Pero además, aun aceptando lo anterior, no es en absoluto tan evidente como Nietzsche pretende que el devenir no pueda ser conocido. La ciencia ha mostrado, al menos desde la invención del cálculo infinitesimal, tener recursos suficientes para describir, entender y manejar el cambio.

Sin embargo, donde Nietzsche pone el énfasis es más bien en el frente epistémico, y es ahí donde su argumento adquiere claramente la forma de «la Joya». El argumento principal de Nietzsche para mostrar que la realidad es incognoscible se basa en la idea de que estamos atrapados en nuestros lenguajes. Dicho argumento puede ser reconstruido del siguiente modo:

1. No podemos inferir legítimamente que nuestras palabras obedezcan o estén causadas por algo externo a nuestra mente (cf. WL). Permanecemos siempre en los límites de nuestro lenguaje y de nuestra perspectiva.

2. Nuestro lenguaje sólo nos permite hablar de las cosas metafóricamente y mediante oposiciones y conceptualizaciones antropomórficas. Es un lenguaje basado en la experiencia humana y ha evolucionado para servir a nuestras necesidades e intereses.

3. Esto ha hecho que se arraiguen en nosotros de forma inextirpable ciertas ilusiones que han sido útiles para nuestra supervivencia (existencia de objetos permanentes, identidad, causalidad, etc.). Pero estas ilusiones son producto del lenguaje y de nuestra cultura, no de la realidad misma.

Por lo tanto, la realidad es incognoscible para nosotros.

Como puede verse, el argumento de Nietzsche introduce premisas adicionales que son, precisamente, las que suelen faltar en la versión canónica de «la Joya $»^{20}$. Pero esas premisas no consiguen levantar el argumento. Son premisas seriamente cuestionables.

Una primera objeción que podría hacerse es que no se han dado razones suficientes para sostener que estamos siempre atrapados en nuestros lenguajes y que ni siquiera podemos inferir legítimamente que nuestras palabras obedezcan a algo externo a nuestra mente. Desde una perspectiva evolucionista, como la que Nietzsche asume, sería desde luego bastante inverosímil sostener que no tenemos acceso a una realidad extralingüística y que ni siquiera podemos decir que nuestro lenguaje está conectado de algún modo con ella. Pero no es aquí donde puede mostrarse más fácilmente la debilidad del argumento. Hay otros puntos donde cabe cuestionar su validez con más contundencia.

Nietzsche basa su idea de que el lenguaje falsifica el mundo en el hecho de que el lenguaje simplifica la realidad, es antropomórfico y arbitrario. Sin embargo, simplificar no es necesariamente falsear. La trama de puntos negros de dis-

20. Hay un lugar donde Nietzsche reproduce «la Joya» casi en su forma canónica. Es en los KSA XII 2[154], donde escribe: «Pero incluso suponiendo que hubiera un en-sí, algo incondicionado (Unbedingtes), ipor ello mismo no podría ser conocido! Algo incondicionado no puede ser conocido, ipues de otro modo no sería algo incondicionado! Conocer es siempre 'situarse en ciertas condiciones para ello'. Un conocedor tal quiere que aquello que desea conocer no tenga ninguna relación con él y que tampoco la tenga con nadie, con lo cual [...] se da una contradicción entre su querer-conocer y la exigencia de que lo conocido no tenga ninguna relación con él». 
tinto tamaño, unidos o no entre sí, que conforman una imagen fotográfica en las páginas de un periódico, son una simplificación de la realidad, pero los puntos no falsifican la realidad. Cada uno de ellos responde a emisiones electromagnéticas emitidas por el objeto, y por eso, a no ser que se mire la fotografía desde muy cerca, la imagen del objeto es reconocible. Una trama más fina permitiría recoger más aspectos del objeto representado. Si en mi uso cotidiano del lenguaje presumo la existencia de objetos que tienen cierta permanencia en el tiempo, puede que esté simplificando, pero cestoy realmente falseando algo? Cierto es que para tener a algo por un objeto con permanencia temporal hay que poseer determinadas capacidades cognitivas - de las que carecen muchos seres vivos- que centralicen y unifiquen la información que llega por los diversos sentidos. Sin embargo, ese procesamiento de la información no constituye por sí mismo un falseamiento de la realidad. Si creo que dos mesas de un aula son iguales, estoy obviamente simplificando, pero muy posiblemente, en el contexto en que se da mi creencia (el de la vida cotidiana y no el del físico cuántico), es una creencia —una interpretación, si se quiere- suficientemente verdadera. Hay, por otra parte, cosas que son iguales sin más, por ejemplo, un electrón con respecto a otro electrón. Incluso suponiendo que el mundo fuera un devenir permanente, esto no significa que identificar objetos o comparar objetos sea crear ilusiones. Nuestro cuerpo está en un constante devenir y cada año cambia el 98\% de los átomos que lo constituyen, pero sería extravagante pensar que ya no se trata del mismo cuerpo. Decir que mi cuerpo de hoy es el mismo cuerpo de hace un año puede ser una simplificación, una verdad aproximada si se quiere, pero no una falsedad. El devenir no excluye, pues, el mantenimiento de cierta identidad, de cierto orden.

Es cierto también que utilizamos conceptos antropomórficos y arbitrarios para describir la realidad, pero ¿̇por qué ha de implicar ello que falsean la realidad? Hablar de la existencia de plantas venenosas puede ser antropomórfico y arbitrario (antropomórfico porque se las clasifica por el efecto que producen en nosotros y arbitrario porque podíamos haber elegido otros nombres y otras clasificaciones). Ahora bien, como sostiene Richardson, «admitiendo una simplificación y falsificación general de las cosas (desde un mundo de devenir a un mundo de ser), 'es verdad' que ciertas plantas son nutritivas, otras venenosas, y es importante conocer esta verdad» (Richardson 1996: 242). En su idea de que el lenguaje nos ofrece siempre un mundo falsificado, Nietzsche toma como errores, falsedades o ilusiones, según los casos, lo que siendo menos estrictos podríamos considerar sencillamente como aproximaciones. Es cierto que no hay objetos absolutamente permanentes -incluso las estrellas cambian constantemente y tienen un principio y un fin-; ni, fuera del mundo cuántico, hay objetos completamente iguales. No obstante, de ahí no se sigue que considerar dos objetos como iguales para un determinado propósito y contexto, o como permanentes en un tiempo razonable, sea forjar una ilusión. Stack (2005: 114) sugiere al menos, aunque no profundiza en la crítica, que, con respecto a la ciencia, Nietzsche se extralimita: «Donde [Nietzsche] es más incauto o atrevido - escribe- es en su tajante afirmación de que los conceptos, principios y leyes empleados en las ciencias son todos ficticios y en su renuencia a admitir, excepto ocasionalmente, que son 'aproximaciones' a la estructura del mundo físico».

Como hemos dicho más arriba, desde consideraciones evolucionistas no hay, al menos por el momento, bases suficientes para sostener un realismo epistemoló- 
gico (pero tampoco un antirrealismo epistemológico). Sí podría decirse, en cambio, que el evolucionismo apoya el perspectivismo, pero un perspectivismo más débil que el nietzscheano. El estudio de la evolución de ciertas especies animales nos enseña que se dan limitaciones o constreñimientos cognitivos que hacen que la información que una especie recibe del entorno sea muy distinta de la que reciben otras especies. Así, algunas especies perciben los rayos ultravioletas, o los infrarrojos; otras tienen sensores para detectar campos electromagnéticos; otras son incapaces de centralizar en una representación única la información que les llega, etc. Es cierto, pues, que nuestro aparato sensorial, y nuestros mecanismos cognitivos en general, nos constriñen dentro de una perspectiva delimitada, diferente a la de otras especies, e imposible de intercambiar. Como señalaba Thomas Nagel, no podemos saber qué es ser como un murciélago. No obstante, esto no implica que esas informaciones parciales y seleccionadas de forma diferente hayan de ser falsas, que lo que los organismos perciben del mundo sea una «ilusión». Por seleccionadas, parciales y tamizadas que estén por nuestros sentidos y nuestras capacidades fisiológicas y mentales, se trata de informaciones que recabamos del mundo, y responden, por tanto, a una realidad exterior. En algunas ocasiones podrán ser falsas, dado que nuestros sentidos son falibles y limitados, y están sujetos por tanto a ilusiones. Pero nada excluye en principio que en otras muchas ocasiones estas informaciones puedan ser verdaderas, especialmente cuando concuerdan las informaciones recibidas por diferentes sentidos. A diferencia de lo que Nietzsche piensa, una perspectiva puede ser parcial, unilateral, subjetiva y aun así podría proporcionar un conocimiento suficientemente verdadero. No hace falta tener el punto de vista del ojo de Dios para acceder a verdades sobre el mundo.

No obstante, la aceptación del hecho evolutivo sí presupone la aceptación de un realismo ontológico básico. Sin un mundo independiente del sujeto carece de sentido hablar de adaptación a un medio. Si nuestras capacidades cognitivas han surgido como rasgo adaptativo a un determinado entorno, es evidente que este entorno no puede ser un producto de nuestras capacidades cognitivas. Esto no significa, por supuesto, que el entorno sea por completo independiente de las actividades de los seres vivos que lo pueblan. Todos los seres vivos modifican su entorno y, por tanto, el proceso de adaptación a un medio es siempre un camino de doble sentido. El entorno hace que ciertos rasgos sean seleccionados en lugar de otros, pero, al mismo tiempo, los organismos hacen que, dentro de ciertos límites, el entorno se adecue a sus necesidades y se torne menos hostil. La tecnología humana es el caso más claro de esta actuación sobre el entorno, pero hasta las lombrices, como bien sabía Darwin, que realizó una detallada investigación al respecto, modifican notablemente el suelo en el que viven.

\section{CONCLUSIONES}

La estrategia epistémica de Nietzsche para sustentar su ficcionalismo se basa en un enfoque evolucionista del conocimiento y del lenguaje. Sin embargo, Nietzsche no proporciona argumentos convincentes desde un punto de vista evolucionista para sustentar su tesis de la falsificación, con lo cual su argumento, de hecho, repite el error de la estructura argumental que Stove denomina «la Joya» o «el peor argumento del mundo». 


\section{AGRADECIMIENTOS}

Este trabajo fue concebido e iniciado durante una estancia de investigación en el Real Colegio Complutense en la Universidad de Harvard durante los meses de febrero, marzo y abril de 2007. Agradezco a su director, Ángel Saenz Badillos, a la Coordinadora de Programas, Elizabeth Kline, y al resto de los investigadores que estuvieron allí durante ese tiempo el ambiente de trabajo y de estímulo intelectual que me proporcionaron. Agradezco igualmente al director del Departamento de Filosofía de la Universidad de Harvard, el profesor Richard Moran, y al profesor Peter Godfrey-Smith, la amable acogida que me dispensaron en dicho departamento. Una versión previa de este trabajo fue leída por Carlos Castrodeza, José María Herrera, Mabel Salido. Todos ellos hicieron observaciones que ayudaron a mejorarlo, incluyendo alguna enmienda a la totalidad que, evidentemente, y bajo mi propia responsabilidad, no atendí.

\section{REFERENCIAS BIBLIOGRÁFICAS}

Anderson, L. R., 1996, «Overcoming Charity: the Case of Maudemarie Clark's Nietzsche on Truth and Philosophy»: Nietzsche-Studien 25, 307-341.

Anderson, L. R., 1998, «Truth and Objectivity in Perspectivism»: Synthese 115, 1-32.

Anderson, L. R., 1999, "Nietzsche's Views on Truth and the Kantian Background of his Epistemology», en B. Babich (ed.), Nietzsche, Theories of Knowledge, and Critical Theory: Nietzsche and the Sciences II, Dordrecht: Kluwer, pp. 47-59.

Babich, B. E., 1999a, "Nietzsche's Critical Theory: The Culture of Science as Art», en B. Babich (ed.), Nietzsche, Theories of Knowledge, and Critical Theory: Nietzsche and the Sciences I, Dordrecht: Kluwer, pp. 1-26.

Babich, B. E., 1999b, «Truth, Art, and Life: Nietzsche, Epistemology, Philosophy of Science», en B. Babich (ed.), Nietzsche, Theories of Knowledge, and Critical Theory: Nietzsche and the Sciences II, Dordrecht: Kluwer, pp. 1-24.

Blackburn, S., 2005, Truth. A Guide, Oxford: Oxford University Press.

Brobjer, T. H,. 2004, «Nietzsche's Reading and Knowledge of Natural Science: An Overview», en G. Moore \& T. H. Brobjer (eds.), Nietzsche and Science, Aldershot: Ashgate, pp. 21-50.

Brown, R. S. G., 2004, «Nietzsche: 'That Profound Physiologist'», en G. Moore \& T. H. Brobjer (eds.), Nietzsche and Science, Aldershot: Ashgate, pp. 51-70.

Clark, M., 1990, Nietzsche on Truth and Philosophy, Cambridge: Cambridge University Press.

Cox, Ch., 1999, Nietzsche: Naturalism and Interpretation, Berkeley: University of California Press.

Danto, A., 1980, Nietzsche as Philosopher, New York: Columbia University Press (1. ${ }^{\mathrm{a}}$ ed. 1965).

Dennett, D., 1995, Darwin's Dangerous Idea, London: Penguin Books.

Diéguez, A., 2002, "Realismo y epistemología evolucionista de los mecanismos cognitivos»: Crítica 34/102, 3-28.

Diéguez, A., 2005, Filosofía de la ciencia, Madrid: Biblioteca Nueva.

Diéguez, A., 2007, «La relatividad conceptual y el problema de la verdad: Bases para un realismo ontológico moderado»: Contrastes 12, 71-91.

Franklin, J., 2002, «Stove's Discovery of the Worst Argument in the World»: Philosophy $77,615-624$. 
Goldman, A. H., 1990, «Natural Selection, Justification, and Inference to the Best Explanation», en N. Rescher (ed.), Evolution, Cognition, and Realism, Lanham, Maryland: University Press of America, pp. 39-46.

Hales, S. D. y Welshon, R., 2000, Nietzsche's Perspectivism, Urbana: University of Illinois Press.

Herrmann-Pillath, C., 1993, «New Knowledge as Creation: Notes When Reading Nietzsche on Evolution, Power, and Knowledge»: Journal of Social and Evolutionary Systems 16/1, 25-43.

Kaufmann, W., 1975, Nietzsche: Philosopher, Psychologist, Antichrist, 4. ${ }^{\mathrm{a}}$ ed., Princeton, NJ: Princeton University Press.

Kitcher, Ph., 2001, Science, Truth, and Democracy, Oxford: Oxford University Press.

Lorenz, K., 1989, La otra cara del espejo. Ensayo de una historia natural del conocimiento humano, trad. de C. Gancho, Barcelona: Círculo de Lectores.

Moore, G., 2002, Nietzsche, Biology and Metaphor, Cambridge: Cambridge University Press.

Musgrave, A., 1999, "Conceptual Idealism and Stove's Gem», en Essays on Realism and Rationalism, Amsterdam: Rodopi.

Nola, R., 2003, Rescuing Reason. A Critique of Anti-Rationalist Views of Science and Knowledge, Dordrecht: Kluwer.

O'Hear, A., 1984, "On What Makes an Epistemology Evolutionary», en Proceedings of the Aristotelian Society, sup. vol. 58, 193-217.

Putnam, H,. 1990, Realism with a Human Face, Cambridge, Mass.: Harvard University Press.

Putnam, H., 1994, Words and Life, Cambridge, Mass.: Harvard University Press.

Rescher, N., 1990, A Useful Inheritance. Evolutionary Aspects of the Theory of Knowledge, Savage, Maryland: Rowman \& Littlefield.

Richardson, J., 1996, Nietzsche's System, New York: Oxford University Press.

Rorty, R., 2000, «Universality and Truth», en R. B. Brandom (ed.), Rorty and His Critics, Oxford: Blackwell, pp. 1-30.

Smith, C. U. M., 1987, “'Clever Beasts Who Invented Knowing’: Nietzsche’s Evolutionary Biology of Knowledge»: Biology and Philosophy 2, 65-91.

Schacht, R., 1983, Nietzsche, London: Routledge.

Schrift, A. D., 1985, «Language, Metaphor, Rhetoric: Nietzsche's Deconstruction of Epistemology»: Journal of the History of Philosophy 23/3, 371-395.

Stack, G. J., 2005, Nietzsche's Anthropic Circle. Man, Science, and Myth, Rochester, NY: University of Rochester Press.

Stich, S., 1990, The Fragmentation of Reason, Cambridge, Mass.: The MIT Press.

Stich, S., 1994, "Could Man Be an Irrational Animal?», en H. Kornblith (ed.), Naturalizing Epistemology, Cambridge, Mass.: The MIT Press.

Stove, D., 1991a, «Idealism: A Victorian Horror-story (Part Two)», en D. Stove, The Plato Cult and Other Philosophical Follies, Oxford: Blackwell, pp. 135-177.

Stove, D., 1991b, “'I only am escaped alone to tell thee': Epistemology and the Ishmael Effect", en D. Stove, The Plato Cult and Other Philosophical Follies, Oxford: Blackwell, pp. 61-82.

Stove, D., 1995, "Judge's Report on the Competition to Find the Worst Argument in the World», en D. Stove, Cricket versus Republicanism and Other Essays, Sidney: Quakers Hill Press, pp. 66-67.

Thomson, P., 1995, «Evolutionary Epistemology and Scientific Realism»: Journal of Social and Evolutionary Systems 18/2, 165-191.

Westphal, K. R., 1984, «Was Nietzsche a Cognitivist?»: Journal of the History of Philosophy 22/3, 343-363.

Wilcox, J. T., 1982, Truth and Values in Nietzsche: A Study in His Metaethics and Epistemology, Washington, D.C.: University Press of America. 
Wilson, D. S., 1990, «Species of Thought: A Comment on Evolutionary Epistemology»: Biology and Philosophy 5, 37-62.

Wuketits, F. M., 1990, Evolutionary Epistemology and Its Implications for Humankind, Albany, N.Y.: SUNY Press.

Zárate, M., 2000, «Nietzsche y las teorías evolutivas»: Diálogo filosófico 48, 413-424.

Zimmerli, W. C., 1999, "Nietzsche's Critique of Truth and Science: A Comprehensive Approach", en B. Babich (ed.), Nietzsche, Theories of Knowledge, and Critical Theory: Nietzsche and the Sciences II, Dordrecht: Kluwer, pp. 253-277. 